\title{
EDITORIAL
}

\section{La indicación farmacéutica, un servicio profesional farmacéutico para reforzar la vertiente clínica y asistencial de la farmacia}

\author{
Jesús C. Gómez Martínez \\ Coordinador del grupo de Indicación Farmacéutica de SEFAC.
}

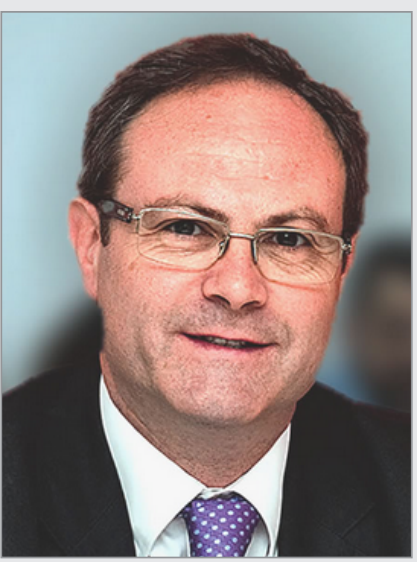

Jesús C. Gómez Martínez

\section{PALABRAS CLAVE}

Indicación farmacéutica, servicio profesional farmacéutico

\section{ABREVIATURAS}

Fl: Farmacia intervención

FC: Farmacia control

SIF: Servicio de Indicación

Farmacéutica

SIFAC: Servicio profesional farmacéutico de Indicación Farmacéutica de SEFAC

\section{KEYWORDS}

Minor ailment service, Community Pharmacy Service
La Atención Farmacéutica se basa en tres pilares básicos: dispensación, seguimiento farmacoterapéutico e indicación farmacéutica. Esta última requiere una gran importancia, dado que entre el 9 y el $16 \%$ de las intervenciones en la farmacia comunitaria se refieren a ella (1).

El documento de Consenso del Ministerio de Sanidad 2001 define indicación farmacéutica como el servicio que el farmacéutico realiza cuando el paciente consulta al farmacéutico comunitario sobre un posible tratamiento para un problema de salud concreto. Es decir, le pregunta "¿qué me da para...?". En este caso siempre referido a aquellos síntomas o sindromes autolimitados para los cuales la legislación permite la dispensación de un medicamento sin prescripción médica. También podrá suponer la derivación al médico en caso necesario (2).

Posteriormente el Foro de Atención Farmacéutica definió la indicación farmacéutica como un servicio demandado habitualmente en la farmacia, en el que el farmacéutico, como agente sanitario, desarrolla un papel fundamental en la mejora/alivio de problemas de salud autolimitados $y_{1}$ en caso de indicar un medicamento que no precisa prescripción médica, optimiza el uso de la medicación (3).

Después de estas definiciones nos podríamos preguntar: ¿es lo mismo efectuar una indicación farmacéutica que tener en la farmacia un servicio de indicación farmacéutica?

Para contestar esa pregunta SEFAC, junto al grupo de investigación de Atención Farmacéutica de la Universidad de Granada y el Muy llustre Colegio Oficial de Farmacéuticos de Valencia pusieron en marcha el estudio de indicación farmacéutica INDICA+PRO. Evaluación del impacto clínico, humanistico y económico del Servicio de Indicación Farmacéutica (SIF) en el ámbito de la Farmacia Comunitaria (4). Este estudio fue un ensayo controlado aleatorizado por conglomerados con un protocolo de codiseño donde participaron médicos y farmacéuticos diferenciando dos grupos:

a) Farmacia intervención (FI), donde se desarrollaba la indicación farmacéutica después de una formación y donde se aplicaban los protocolos consensuados entre las sociedades científicas.

b) Farmacias control (FC), donde se efectuaba la indicación farmacéutica según lo hacian de forma habitual. 
Los resultados fueron que:

- Fl derivó al centro de salud el doble que el FC.

- Fl cambió el tratamiento demandado el doble de veces que el FC.

El ahorro estimado en Farmacia Comunitaria de la aplicación del servicio de indicación farmacéutica fue de entre 30 millones de euros y 121 millones de euros anuales en la Comunidad Valenciana a través de la transferencia de consultas por sintomas menores del centro de salud a la farmacia comunitaria, incluyendo la remuneración correspondiente a la farmacia.

Con estos datos contundentes se ha puesto en marcha el estudio Implantación del servicio de indicación farmacéutica en toda España donde participan mas de 700 investigadores con más de 13.000 registros hasta la fecha, a pesar de estar en un período de pandemia por la COVID-19.

A partir del mes de febrero, y posteriormente con las ediciones de junio y octubre de capacitaciones de servicios profesionales de SEFAC, los farmacéuticos comunitarios que lo deseen podrán capacitarse en el servicio SIFAC: Servicio Profesional Farmacéutico de Indicación Farmacéutica de SEFAC, que cuenta además con el aval de las principales sociedades científicas médicas de atención primaria.

La Organización Mundial de la Salud (OMS) concluia en 2009 (5) que el autocuidado debe ser un componente fundamental para conseguir objetivos en salud, siendo importante no solo para reducir costes sino también para mejorar el acceso al sistema sanitario.

Por el impacto en salud demostrado en el estudio INDICA+PRO, las recomendaciones de organismos como la OMS, la experiencias de paises donde ya lo tienen implantado como Canadá o Reino Unido y porque la indicación farmacéutica que se efectúa de forma presencial en la farmacia comunitaria no puede ni debe ser sustituida por acciones digitales es necesario desarrollar el servicio de indicación farmacéutica SIFAC que, sobre todo y lo más importante, tiene un impacto en la mejora de la salud del paciente y en el autocuidado de la salud de la población.

Si quieres desarrollar una Farmacia Clínica Comunitaria, el Servicio de Indicación Farmacéutica SIFAC es una gran oportunidad.

\section{REFERENCIAS BIBLIOGRÁFICAS}

1. Prats $R$, Piera V, Pons $L_{1}$ Roig I. Estudio cuantitativo y cualitativo de la indicación farmacéutica en una Farmacia Comunitaria. Pharm Care Esp. 2012; 14: 2-10. Disponible en: https://www.pharmcareesp.com/ index.php/PharmaCARE/article/view/9

2. Foro de Atencion Farmaceutica. Documento de Consenso. Madrid: Consejo General de Colegios Oficiales de Farmaceuticos. 2008. Disponible en: https://www.sefac.org/pdf/consensoforoafcompleto.pdf

3. Foro de Atención Farmacéutica en Farmacia Comunitaria (Foro AFFC). Guia práctica para los Servicios Profesionales Farmacéuticos Asistenciales en la Farmacia Comunitaria. Madrid: Consejo General de Colegios Oficiales de Farmacéuticos. 2019. Disponible en: https:// www.sefac.org/system/files/2021-02/AF_GUIA_SPFA_FORO_2021_ ONLINE_PGs.pdf

4. Amador-Fernández N, Baixauli-Fernández VJ, Climent-Catalá MT, Colomer-Molina V, Garcia-Agudo O, Garcia-Cárdenas MV, et al. INDICA+PRO: informe sobre la evaluación del impacto clínico, humanistico y económico del servicio de indicación farmacéutica en el ámbito de la farmacia comunitaria. Granada: Grupo de Investigación en Atención Farmacéutica; 2019. https://www.sefac.org/system/files/ 2020-01/INDICA\%2BPRO_Informe.pdf

5. World Health Organization. Self-care in the context of primary health care report of the regional consultation. Bangkok: World Health Organization; 2009. Disponible en: https://apps.who.int/iris/bitstream/ handle/10665/206352/B4301. pdf? sequence $=1$ EtisAllowed =y 